\title{
Psychotraumatism in Burning Accident Victims: About 50 Patients at the Abidjan Burns Center
}

\author{
Ahounou Etobo Innocent ${ }^{1,2, *}$, Traore Brahim Samuel ${ }^{1,2}$, Aka Rita Ahou ${ }^{1,2}$, Djo Bi Djo François ${ }^{1,2}$, \\ Gonce Dion Aristide ${ }^{3}$, Yeo-Tenena Yessonguilana Jean-Marie ${ }^{1,2}$ \\ ${ }^{1}$ Nervous System Rehabilitation and Rheumatology Department, Medical Sciences Training and Research Unit, Felix Houphouet-Boigny \\ Abidjan University, Abidjan, Ivory Coast \\ ${ }^{2}$ Addictology and Mental Hygiene Service - National Institute of Public Health (INSP) of Abidjan, Abidjan, Ivory Coast \\ ${ }^{3}$ Abidjan Hospitals Intern (Ivory Coast), Addictology and Mental Hygiene Service - National Institute of Public Health (INSP) of Abidjan, \\ Abidjan, Ivory Coast
}

\section{Email address:}

ahounouinno@gmail.com (A. E. Innocent), samygrande@live.fr (T. B. Samuel), rita_aka@yahoo.fr (A. R. Ahou), djobiradys@yahoo.fr (D. B. D. François), godaris2014@gmail.com (G. D. Aristide) ouandete@gmail.com (Yeo-Tenena Y. Jean-Marie)

${ }^{*}$ Corresponding author

\section{To cite this article:}

Ahounou Etobo Innocent, Traore Brahim Samuel, Aka Rita Ahou, Djo Bi Djo François, Gonce Dion Aristide, Yeo-Tenena Yessonguilana Jean-Marie. Psychotraumatism in Burning Accident Victims: About 50 Patients at the Abidjan Burns Center. American Journal of Psychiatry and Neuroscience. Vol. 9, No. 3, 2021, pp. 143-146. doi: 10.11648/j.ajpn.20210903.22

Received: July 20, 2021; Accepted: August 10, 2021; Published: September 30, 2021

\begin{abstract}
Among the potentially traumatic events, burn accidents have the particularity of damaging the physical integrity of the victims while leaving psychological scars. The objective of this study is to investigate the attribution of post-traumatic stress disorder (PTSD) to the presence of extensive body burn. This was a cross-sectional descriptive and analytical study that took place from May to August 2017 and which involved (50) fifty patients labeled severe burns. The burns were second degree superficial $(63.50 \%)$ and affected between 1 and $10 \%$ of the body surface in $72 \%$ of cases. The event appealed to a sense of horror at the mention (28\%). Post-traumatic stress disorder was found in $6 \%$ of victims. The chi-square test found a significant dependence with a P-value of 0.0043 between the PTSD score and the body surface area burned. The extent of the burn injuries in the victims, in addition to reflecting the severity of the accident, is a risk factor associated with the occurrence of psychotrauma. In a dual preventive and therapeutic approach, psychotraumatological follow-up should be offered to any major burn victim.
\end{abstract}

Keywords: Burns Accidents, Major Burns, PCLS Score, Psychotrauma, Abidjan

\section{Introduction}

A burn defined as an injury to the skin and underlying tissue is caused by heat, chemicals or electricity [1].

Each year in the United States, approximately 450,000 people receive medical care for burns [2], while in France, 400,000 cases of burns require medical attention [3].

Burn injuries pose a global public health problem, being responsible for an estimated 180,000 deaths per year. Low and middle income countries are the most affected [4]. A burn is considered severe when it is functionally and/or vitally life-threatening due to its extent, depth, topography, circumstances and causative agent [5]. But beyond the physical injuries and other physical stigmata that they cause, burn accidents are potentially traumatic events.

Yet these psychological sufferings and stigmas are ostracized or neglected during the management of these patients. In some cases, the extent of the skin lesions observed seems to be a burden to the psychotrauma. So what is the prevalence of psychotrauma in burn patients? Can the extent of skin burns be considered a factor in the occurrence of PTSD in burn victims? To answer these questions, this study was conducted to investigate the link between the extent of skin burns and psychotrauma in accident victims followed at the Abidjan burn center.

\section{Materials and Methods}

This was a descriptive and analytical cross-sectional study 
conducted at the Abidjan burns center (attached to the Emergency Medical Service) from May to August 2017 on a population of 50 patients.

We used the non-probability sampling method by reasoned choice, i.e., accidental sampling, i.e., the sample was constituted on the basis of the possibility of encounters with patients with severe burns. Patients with burns of at least one month duration, aged over 15 years and in the healing phase during the study period were included. These patients were subjected to the Post Traumatic Stress Disorder Checklist Scales (PCLS). Cross-tabulations by chi-square statistical test were performed and a value of $\mathrm{P}<0.05$ was considered significant.

\section{Results}

\subsection{Sociodemographic Characteristics}

The socio-demographic data show that the majority of the respondents were men (58\%) and were between 26 and 35 years old in $46 \%$ of cases. More than half of the patients $(56 \%)$ worked in the informal sector and had an activity exposing them to fire in $60.71 \%$ of cases.

\subsection{Clinical Characteristics of the Burn Accident}

Table 1. Distribution of patients by clinical.

\begin{tabular}{lll}
\hline Burns data & & \\
\hline Causes of burns & Staff $(\mathrm{n}=50)$ & $\%$ \\
thermal & 47 & 94 \\
Electric & 03 & 06 \\
Circumstances of occurrence & & \\
Domestic accident & 27 & 54 \\
Workplace accident & 23 & 46 \\
Topography of the lesions & Frequency $(\mathrm{n}=151)$ & $\%$ \\
Head & 20 & 13,24 \\
Neck & 06 & 04,00 \\
Chest & 16 & 10,60 \\
Arm & 10 & 06,62 \\
Forearm & 21 & 13,90 \\
Hand & 23 & 15,23 \\
External genitalia & 02 & 01,32 \\
Buttock & 05 & 03,31 \\
Thigh & 16 & 10,60 \\
Leg & 20 & 13,24 \\
Foot & 12 & 07,94 \\
Degree of burn & Fréquency $(\mathrm{n}=63)$ & $\%$ \\
1st degree superficial & 11 & 17,50 \\
2nd degree superficial & 40 & 63,50 \\
2nd degree intermediate & 12 & 19 \\
Body surface burned & Staff $(\mathrm{n}=50)$ & 72 \\
0-10\% & 36 & 20 \\
11-20\% & 10 & 08 \\
\hline $20 \%$ & 04 & \\
\hline & & 0 \\
\hline
\end{tabular}

\subsection{Characteristics Related to Psychotrauma}

Table 2. Distribution of respondents by PCL-S score.

\begin{tabular}{lll}
\hline PCL-S score & Staff $(\mathbf{n}=\mathbf{5 0})$ & Percentage $\mathbf{( \% )}$ \\
\hline Score $17-33$ & 34 & 68,00 \\
Score $34-42$ & 13 & 26,00 \\
Score $\geq 43$ & 03 & 06,00 \\
\hline
\end{tabular}

Table 3. Cross-reference between PTSD and feelings.

\begin{tabular}{lllll}
\hline $\begin{array}{l}\text { Score PTSD / feeling } \\
\text { of the event }\end{array}$ & $\begin{array}{l}\text { Score } \\
\mathbf{1 7 - 3 3}\end{array}$ & $\begin{array}{l}\text { Score } \\
\mathbf{3 4 - 4 3}\end{array}$ & $\begin{array}{l}\text { Score } \\
\mathbf{2 4 4}\end{array}$ & Total \\
\hline Difficult & 17 & 7 & 1 & 25 \\
horrible & 2 & 0 & 2 & 4 \\
Shocking & 3 & 3 & 0 & 6 \\
Awful & 2 & 0 & 0 & 2 \\
Painful & 1 & 0 & 0 & 1 \\
Unfortunate & 11 & 0 & 0 & 11 \\
Tragic & 1 & 0 & 0 & 1 \\
Total & 37 & 10 & 3 & 50 \\
The dependence is highly significant, chi2 $=23,90, d d l=12, p=0,021$. \\
\hline
\end{tabular}

\subsection{Growth of PTSD Score with Body Surface Burned}

Table 4. Cross-tabulation of PTSD score with body surface area burned.

\begin{tabular}{lllll}
\hline PTSD score/Body & Score & Score & Score & Total \\
surface area burned & $\mathbf{1 7 - 3 3}$ & $\mathbf{3 4 - 4 3}$ & $\mathbf{2 4 4}$ & \\
\hline$[0 \% 10 \%]$ & 31 & 4 & 1 & 36 \\
{$[10 \% 20 \%]$} & 5 & 3 & 2 & 10 \\
$>20 \%$ & 1 & 3 & 0 & 4 \\
Total & 37 & 10 & 3 & 50 \\
The dependence is highly significant, chi2 $=14.89, d d l=4, p=0.0049$. \\
\hline
\end{tabular}

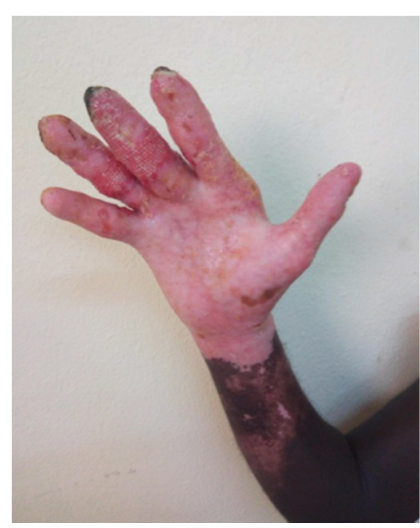

Figure 1. Study patient with a 2nd degree intermediate burn on the right hand $c$.

\section{Discussion}

Burn accidents affected male subjects in $58 \%$ of cases, with a ratio of 1.38. These results are consistent with those of El Yaacoubi [6] who found 59\% males versus $41 \%$ females and Ibnouzahir [7] who noted a sex ratio of 1.18 in favor of males. Batra and al [8]. Found that although men had a higher incidence of injury for various injury mechanisms, women had a higher rate of death from burns than men.

Men would be more exposed to burn accidents because they are more often involved in occupations that expose them to thermal sources (ironworker, sheet metal worker). In fact, among the $56 \%$ of our respondents who worked in the informal sector, $60 \%$ of them had a job that exposed them to fire.

However, the work environment was not the only place where these accidents occurred. In fact, $54 \%$ of the accidents occurred at home. El Yaacoubi [6] also found a predominance of domestic accidents in $59.5 \%$ of cases. Notwithstanding the presence of causal agents in the 
domestic setting, the absence of extinguishing means, their precariousness, coupled with the carelessness of the population in handling certain causal agents, especially thermal (almost all burns, i.e. 94\%, had a thermal origin), could favor the occurrence of fire.

The age of the burned patients was for the majority (46\%) between 26 and 35 years. El Yaacoubi [6] in his work noted that $49.5 \%$ of burn victims were between 20 and 40 years of age with a peak between 30 and 40 years. This segment of the population being the most active, is therefore the most exposed to burn accidents.

The clinical data on burns showed that the burns were located on the hand (15.23\%), forearm (13.90\%), head $(13.24 \%)$ and leg (13.24\%). D. Wassermann [9] also reports that hand burns are the most common. Indeed, the hand, the organ of grip and protection in the survival instinct, is logically the most affected during burns. On the other hand, the study carried out by the Institut de Veille Sanitaire [10] showed that regardless of age and sex, the most frequently injured parts were the head and neck $(20 \%)$, the wrist and hand $(18 \%)$ and the trunk (13\%). In this study, the predominance of head and neck injuries could be explained by the fact that it was carried out in a hospital setting where facial burns are frequently found and are generally severe.

According to the severity criteria, $63.5 \%$ of the victims had superficial second degree burns (Table 1). In addition to the degree of burns, 14 of the victims had more than $10 \%$ of their body surface burned. And precisely $8 \%$ had burns of more than $20 \%$ of the body surface. (Table 1). Our results are clearly inferior to those of Tadili [5] who reported $39.8 \%$ for burns of 10 to $20 \%$ and $40.7 \%$ for burns of more than $20 \%$.

The evaluation of the feeling during the burn accident, finds a feeling of horror in $28 \%$ of the respondents. In fact, the characteristics of a potentially traumatic event include the feeling of horror experienced by the patient during exposure to the traumatic stimulus. But some people go through objectively painful experiences without the spectre of trauma looming over them. On the other hand, and this is sometimes more difficult to understand for the uninitiated, "minor" events can be the cause of undeniable psychopathological complications. It is only by going to meet the subject, after the event and in the time that follows, that this suffering can be identified.

The multiplicity of reactions following the event is such that it is indeed very difficult to establish a prognosis a priori: it is not necessarily those who express the most emotion immediately after the event who are the most affected. The factors that account for what is traumatic for one person and not for another depend on certain characteristics of the event and its course. For example, a house fire may be experienced very differently if the subject is surprised by the fire or not, if he is alone or accompanied by his family.

The application of the PCL-S scale to the patients in the study specifically found $6 \%$ of the victims with a score above 43 (Table 2). This score indicates the presence of a PostTraumatic Stress Disorder. Magne et al. [11] reported in their work that $8.25 \%$ of burned patients presented a post-traumatic stress state. However, it should not be forgotten that the $26 \%$ who had a score between 34 and 43 were also at risk of developing PTSD. As an illustration, a study on the psychology of burn victims, carried out by Eric Bonvin and Pierre Cochand [12], found that more than one third of burn victims developed a complete post-traumatic stress disorder during the year following their discharge from hospital. According to the literature [13, 14], 3\%-58\% of burn survivors develop symptoms of PTSD and approximately $50 \%$ of them report suffering from at least one of the PCL-S items. It is important to keep in mind that PTSD symptoms do not always manifest early in burn victims, and may appear up to several months after the injury [15]. This shows that the onset of PTSD takes place over time; it is a deferred PTSD, hence the need to follow up burn victims over the long term.

The analytical study carried out allowed us to use the chisquare test, the cross-tabulation score of PTSD and the feeling of the event experienced, indicated a $\mathrm{P}_{-}$value of 0.021 lower than $0.05(5 \%)$, hence a significant dependence (Table 3). Logically, a feeling of horror experienced by victims of an accident involving exposure to fire or a thermal agent would constitute a de facto predictive factor for PTSD.

A second cross-tabulation between PTSD and burned body surface area shows a significant dependence with a $\mathrm{P}_{-}$value at 0.0043 or 0.0049 much lower than 0.05 (5\%). This could reflect that the occurrence of PTSD in a burn victim is correlated with the burned body surface area (Table 4). These results are in line with those of Sadeghi-Bazargani et al [16] who reported an association between total body surface burned and PTSD. Palmu et al [17] in their study of mental disorders in burn victims confirmed this correlation between anxiety disorder and total body surface burned. The traumatogenic potential of the burn injury would thus be dependent on the extent of the burned body surface.

\section{Conclusion}

The profile of burn victims followed at the Abidjan Burns Centre is that of a male subject aged between 26 and 35 years and working in an informal occupation exposed to fire. The clinical examination showed a second-degree thermal burn of the hand, forearm, head and leg.

The prevalence of PTSD according to the PCL-S scale was $6 \%$ in our respondents followed at the burn center. This occurrence of PTSD is related to the experience of the traumatic event but also to the extent of the burned body surface. The extent of the body injuries is often a source of self-esteem failure.

In the treatment of the burned patient, the psychological follow-up is imperative for a global management of these patients, hence the need for a liaison psychiatry.

In a double preventive and therapeutic approach, a psychotraumatological follow-up will have to be proposed to any burned patient. 


\section{Conflicts of Interest}

The authors declare that they have no conflicts of interest.

\section{References}

[1] American Burn Association. Advanced burn life support course. Provider Manual 2018 update.

[2] Bourgeois E, Losser MR. Severe burns. Emergency 2012.

[3] French-speaking society of burns. Prevention of burns. Burn care 2019.

[4] World Health Organization. Burns Fact Sheet No. 365 March 2018. http://www.who.int/mediacentre/factsheets/fs365/fr. Accessed on 05/12/2020.

[5] Tadili MA. Severe burns in adults in the acute phase: epidemiological study and practical therapeutic attitudes. Thesis Doctorate in Medicine, Marrakech; 2016, N 19, 197 pages.

[6] El Yaacoubi R. The management of severe burns in the anesthesia and intensive care unit of Hassan II University Hospital, Fez. Thesis Doctorate in Medicine, Fez; 2020, N ${ }^{\circ}$ 013, 211 pages.

[7] Ibnouzahir M, Ettalbi S. Epidemiological profile of burn victims in Marrakech: about 152 cases. Ann Burns Fire Disasters. 2011 Mar 31; 24 (1): 3-6.

[8] Batra AK. Burn mortality: recent trends and sociocultural determinants in rural India. Burns. 2003; 29: 270-275. [PubMed] [Google Scholar].
[9] Wassermann D. Severity criteria for burns. Epidemiology, prevention, organization of care PatholBiol 2002; 50: 65-73.

[10] Pasquereau, B. Thélot. Hospitalizations for burns from PMSI data, metropolitan France, 2009, Institut de veille sanitaire (InVS); May 2014. P: 1.

[11] Magne J, Rochet JM. Impact of psychological and psychiatric problems on burn rehabilitation work. Burn 2000; 2: 1-4.

[12] Bonvin E, Cochand P. Psychology of the burned, Revue médicale de la Suisse romande, 118, 161-164, 1998.

[13] Van Loey NE, Van Son MJ. Psychopathology and psychological problems in patients with burn scars: epidemiology and management. Am J Clin Dermatol. 2003; 4 (4): 245-272.

[14] Fauerbach JA, Lawrence J, Haythornthwaite J, et al. Preburn psychiatric history affects posttrauma morbidity. Psychosomatics. 1997; 38 (4): 374-385.

[15] Yu BH, Dimsdale JE. Posttraumatic stress disorder in patients with burn injuries. J Burn Care Rehabil. 1999; 20 (5): 426433.

[16] Sadeghi-Bazargani H, Maghsoudi H, Soudmand-Niri M, Ranjbar F, Mashadi-Abdollahi H. Stress disorder and PTSD after burn injuries: a prospective study of predictors of PTSD at Sina Burn Center, Iran. Neuropsychiatric Disease Treatment. 2011; 7: 425-429.

[17] Palmu R, Suominen K, Vuola J, Isometsa E. Mental disorders among acute burn patients. Burns. 2010; 36 (7): 1072-1079. 